\title{
Clinical application of bone morphogenetic proteins for bone healing: a systematic review
}

\author{
Gopal Shankar Krishnakumar ${ }^{1}$ - Alice Roffi ${ }^{1}$ (D) Davide Reale ${ }^{2} \cdot$ Elizaveta Kon $^{3}$ • \\ Giuseppe Filardo ${ }^{1}$
}

Received: 12 December 2016/Accepted: 23 March 2017 / Published online: 19 April 2017

(C) The Author(s) 2017. This article is published with open access at Springerlink.com

\begin{abstract}
Purpose This paper documents the existing evidence on bone morphogenetic proteins (BMPs) use for the treatment of bone fractures, non-union, and osteonecrosis, through a review of the clinical literature, underlying potential and limitations in terms of cost effectiveness and risk of complications.

Methods A systematic review was performed on the PubMed database using the following string: (bone morphogenetic proteins OR BMPs) and (bone repair OR bone regeneration) including papers from 2000 to 2016 . The search focused on clinical trials dealing with BMPs application to favor bone regeneration in bone fractures, non-union, and osteonecrosis, in English language, with level of evidence I, II, III, and IV. Relevant data (type of study, number of patients, BMPs delivery material, dose, site, follow-up, outcome, and adverse events) were extracted and analyzed.

Results Forty-four articles met the inclusion criteria: 10 randomized controlled trials (RCTs), 7 comparative studies, 18 case series, and 9 case reports. rhBMP-2 was documented mainly for the treatment of fractures, and rhBMP-7 mainly for non-unions and osteonecrosis. Mixed results were found among RCTs and comparative papers: 11 reported positive results for BMPs augmentation, 3 obtained no significant
\end{abstract}

Alice Roffi

alice.roffi@ior.it

1 Nano-Biotechnology Laboratory, Rizzoli Orthopaedic Institute, Via di Barbiano 1/10, 40136 Bologna, Italy

2 I Orthopaedic and Traumatologic Clinic, Rizzoli Orthopaedic Institute, Via Pupilli 1, 40136 Bologna, Italy

3 Knee Joint Reconstruction Center - 3rd Orthopaedic Division, Humanitas Clinical Institute, Via Alessandro Manzoni 56, Rozzano, Italy effects, and 2 showed negative results. The only study comparing the two BMPs showed a better outcome with rhBMP-2 for non-union treatment.

Conclusion Clinical evidence on BMPs use for the treatment of fractures, non-union, and osteonecrosis is still controversial, with the few available reports being mainly of low quality. While positive findings have been described in many studies, mixed results are still present in the literature in terms of efficacy and adverse events. The difficulties in drawing clear conclusions are also due to the studies heterogeneity, mainly in terms of different BMPs applied, with different concomitant treatments for each bone pathology. Therefore, further research with well-designed studies is needed in order to understand the real potential of this biological approach to favour bone healing.

Keywords BMPs $\cdot$ Bone $\cdot$ Fractures $\cdot$ Non-union $\cdot$ Osteonecrosis

\section{Introduction}

Bone healing is a complex process that requires the synergistic action of cells, cytokines, and growth factors (GFs) [1, 2]. Over the past few decades, the therapeutic application of GFs for bone regeneration gained increasing attention in the scientific community, for their ability to trigger cells to facilitate intracellular signal transduction for endochondral and intramembranous bone formation [3]. Among several GFs involved in skeletal remodeling and repair, the discovery by Urist of bone morphogenetic proteins (BMPs) at the end of the nineteenth century [4] was of great importance in understanding the complex biological cascade of osteogenesis.

BMPs are extensively studied and widely recognized as key factors in a variety of chondrogenic and skeletogenic 
functions during normal embryonic development [5]. BMPs belong to the transforming growth factor $\beta$ (TGF- $\beta$ ) super family and are considered to be a diverse group of phylogenetically conserved GFs, 20 members of which have been identified so far [6]. Multiple BMPs are considered to have a crucial signalling role in chemotactic proliferation and differentiation of osteoprogenitor cells, thereby inducing bone formation. It has been reported that BMPs play a central role in the regulation of the three major stages of fracture healing (inflammation response, chondrogenic phase, and osteogenic phase); however, the molecular mechanisms of action are still being investigated $[7,8]$. Currently, there are two commercially available BMPs, recombinant human rh BMP-2 and rhBMP-7. They have been tested in several preclinical studies showing the ability to induce bone regeneration [9-11], and evaluated in clinical trials to treat various bone disorders such as non-unions, open fractures, and osteonecrosis [12-17]. The successful application of BMPs led, in July 2002, to the approval by the European Medicines Agency (EMA) of rhBMP-2 (InductOs ${ }^{\circledR}$ ) for the treatment of single-level lumbar spine fusion and for acute tibial fractures in adults [18]. In November 2002, the American Food and Drug Administration (FDA) approved the use of rhBMP-2 (INFUSE® Bone Graft Device) for the treatment of open tibial fractures after stabilization with intramedullary nail (IM) fixation [18]. rhBMP-7 received official approval by EMA in 2004 as Osteogenic Protein-1 (OP-1® or Osigraft $®)$ implant for the treatment of recalcitrant long bone non-unions [19]. Nevertheless, despite early promising results, some severe complications have been reported in clinical setting, such as ectopic bone formation, haematomas in soft tissues, and bone resorption around implants [20-22]. Thus, while BMPs seemed promising for bone regeneration, potential and limitations remains debated.

The aim of this review was to document and summarize the existing evidence on BMPs use for the treatment of bone fractures, non union, and osteonecrosis, through a systematic revision of the clinical literature, underlying potential and limitations in terms of cost effectiveness and risk of complications of this promising approach to favour bone healing.

\section{Materials and methods}

A systematic review was performed by two independent reviewers (GSK and DR) on the PubMed database using the following string: (bone morphogenetic proteins OR BMPs) and (bone repair OR bone regeneration), including papers from 2000 to 2016. An initial screening was performed on all abstracts. The search focused on clinical trials dealing with BMPs application to favor bone regeneration in the treatment of bone fractures, non union, and osteonecrosis, in English language, with level of evidence I, II, III, and IV. In the second step, full texts of the selected articles were screened, with further exclusions according to the previously described criteria. Reference lists from the selected papers were also screened. Relevant data (type of study, number of patients, BMPs delivery material, dose, commercial name, anatomical site, follow-up, outcome, and adverse events) were then extracted and collected in a database with consensus of the two reviewers, to be analyzed for the purposes of the present systematic review. A flowchart of the literature analysis is reported in Fig. 1.
Fig. 1 Flow chart of the systematic literature review

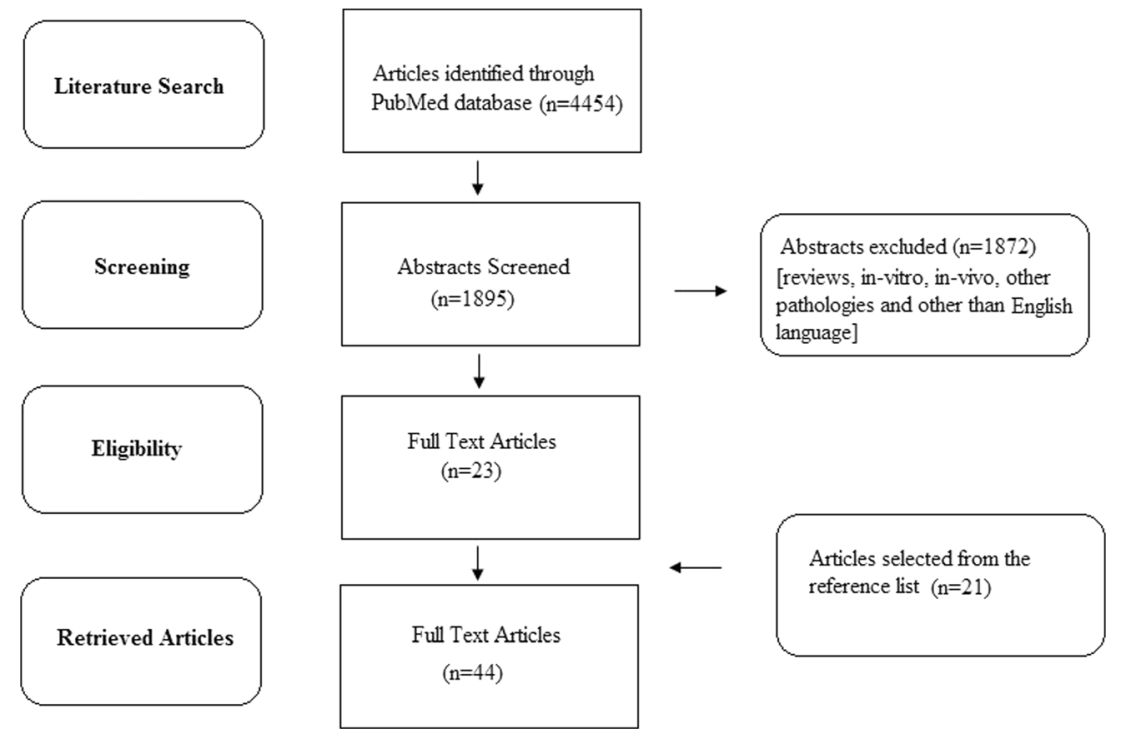




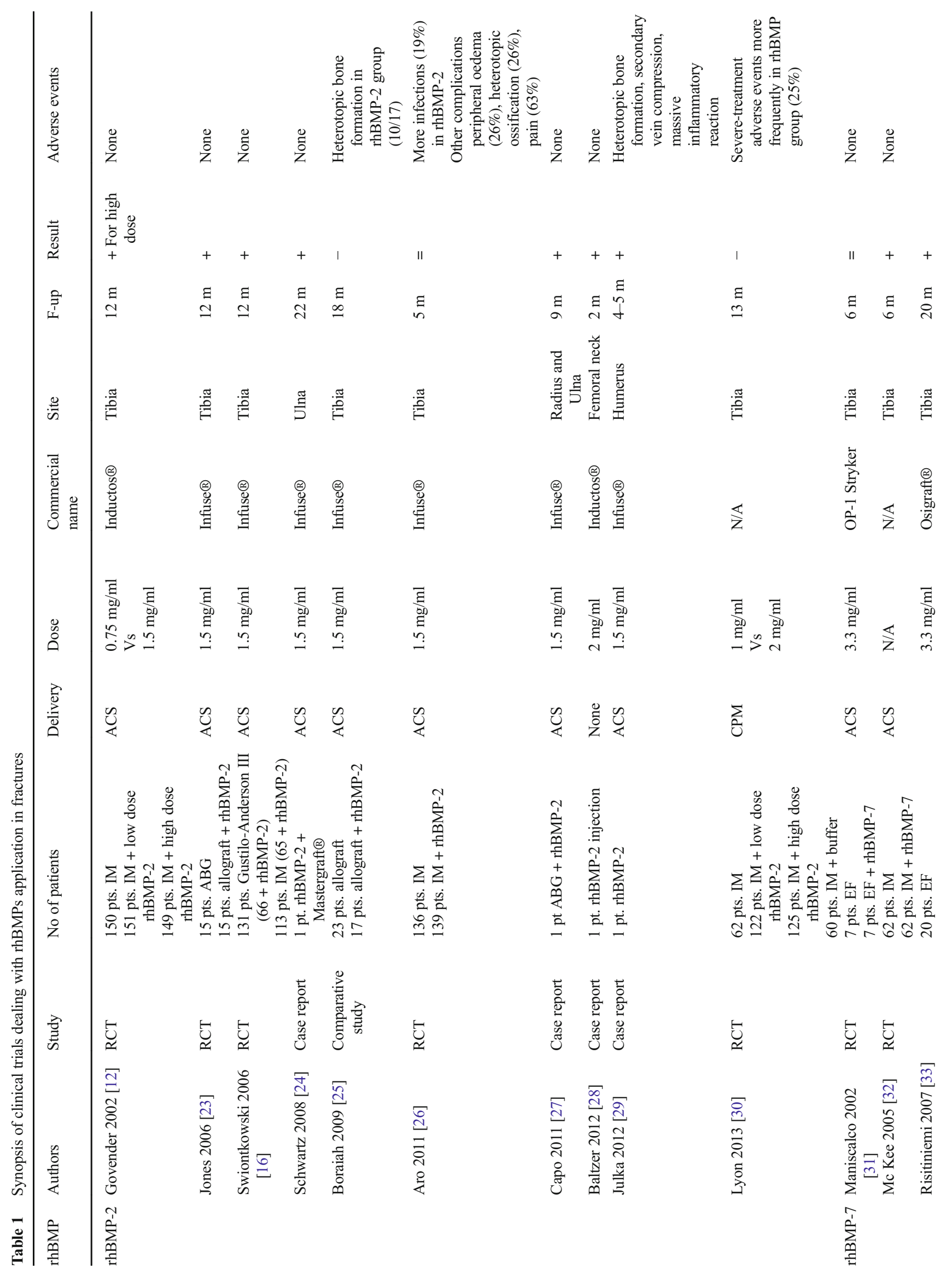


Results

According to the PubMed search analysis, a total of 4454 abstracts were screened and, among these, 44 articles met the inclusion criteria: 10 randomized controlled trials (RCTs), 7 comparative studies, 18 case series, and 9 case reports. This systematic review highlighted that the clinical use of BMPs as biological augmentation for bone regeneration presents a steady interest among physicians with new studies published in recent years. All papers are reported in three different tables according to the pathology considered (Tables 1,2,3), but only randomized trials have been further analyzed and described in the following paragraphs, according to the BMP used and the pathological target.

\section{BMPs and fractures}

The literature search for BMPs use in open fractures found: 7 RCTs, 2 comparative studies, 1 case series, and 5 case reports. With regard to the defect site, 9 papers dealt with tibial fractures, 3 with humeral fractures, 2 with forearm fractures, and 1 with femoral fractures (Table 1).

rhBMP-2 and fractures

In 2002, the BMP-2 Evaluation in Surgery for Tibial Trauma (BESTT) RCT [12] investigated safety and efficacy of rhBMP-2 for the treatment of tibial fractures in 450 patients randomized into three groups: 151 patients received $0.75 \mathrm{mg} /$ $\mathrm{ml}$ of rhBMP-2 enclosed in a bovine derived Absorbable Collagen Sponge (ACS, Helistat; Integra LifeScience, Plainsboro, New Jersey), 149 patients received $1.50 \mathrm{mg} / \mathrm{ml}$ of rhBMP-2 enclosed in ACS, and 150 patients received only IM fixation. After 12 months, rhBMP-2 demonstrated to be safe and effective in accelerating tibial fractures healing at the dosage of $1.5 \mathrm{mg} / \mathrm{ml}$. Overall, the frequency of secondary interventions, the rate of infections, and the invasiveness of the procedures were relatively lower. A subsequent analysis in 2006 [16] on the BESTT study patients plus a United States study group, was conducted taking into account the type of fractures and $1.5 \mathrm{mg} / \mathrm{ml}$ dosage. Subgroup I: 131 patients with Gustilo-Anderson type IIIA or IIIB tibial fractures - 65 patients as IM control group and 66 patients as experimental rhBMP-2 group; and Subgroup II: 113 patients with Gustilo-Anderson type I through type IIIB tibial fractures -48 patients as IM control group and 65 patients as experimental rhBMP-2 group. The subgroup analysis revealed that the addition of rhBMP-2 was able to significantly reduce the frequency of bone grafting procedures and other secondary interventions at 12 months for the treatment of type III tibial fractures. In 2006 Jones et al. [23] investigated the treatment of tibial diaphyseal fractures associated with substantial bone loss in 30 patients: 15 patients with autolo- 


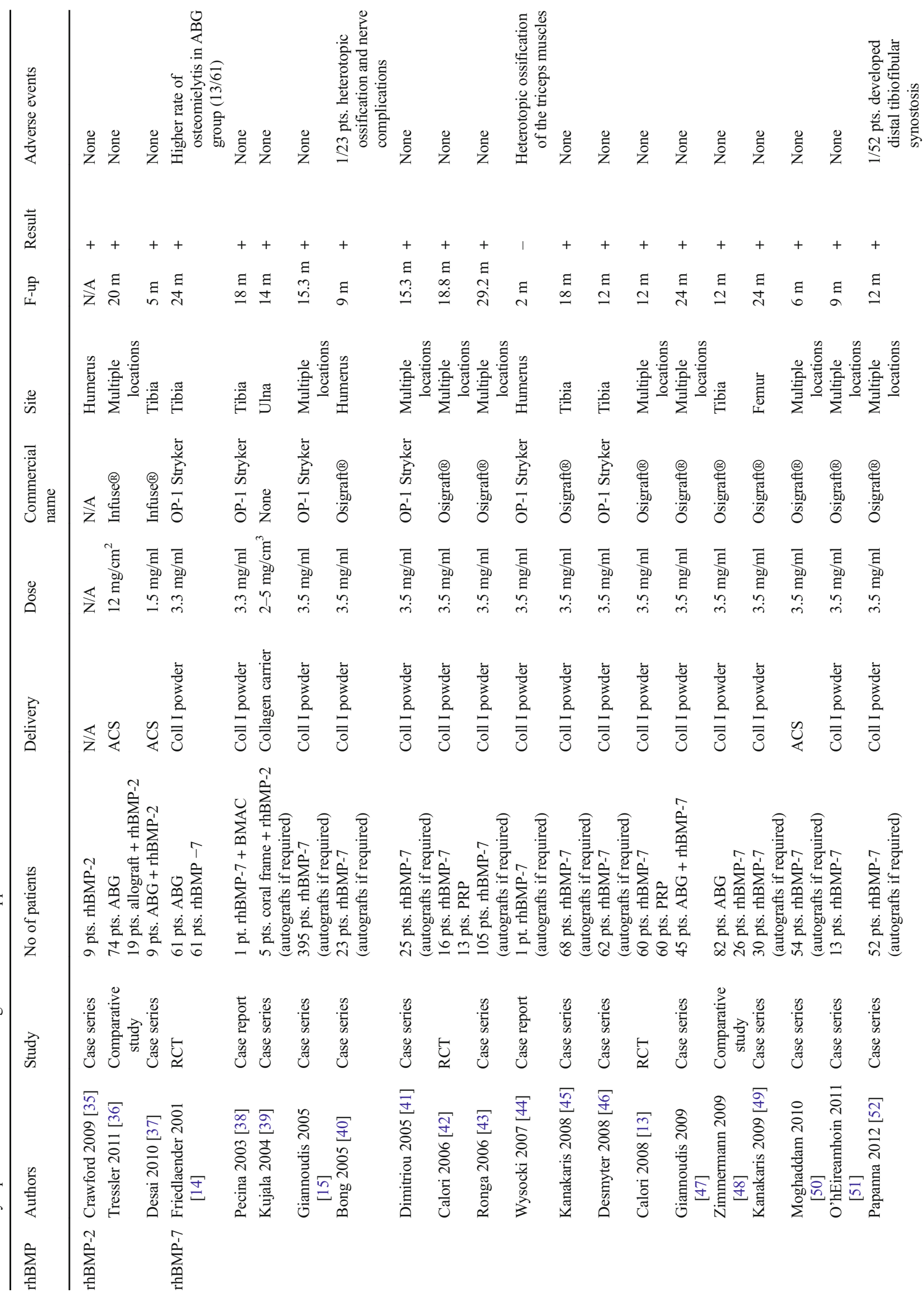




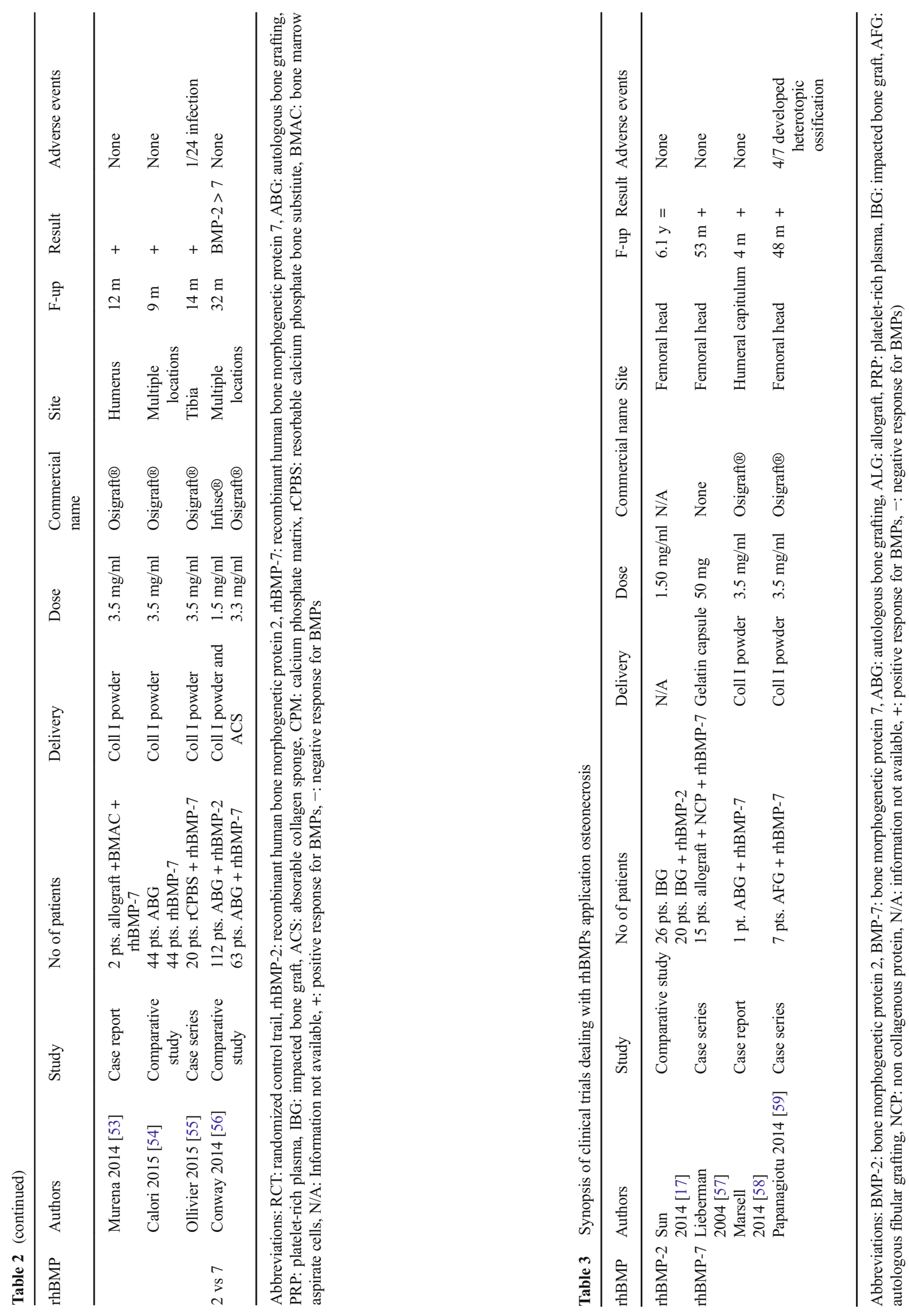


gous bone graft $(\mathrm{ABG})$ and 15 with rhBMP-2 in combination with allograft. At 12 months, there was no significant difference in healing rate, bone-graft integration, and improvement in quality of life scores, underlying that the combination of rhBMP-2/allograft is a clinically beneficial and a safe alternative to $\mathrm{ABG}$ for tibial fractures with extensive traumatic diaphyseal bone loss. A large RCT was performed in 2011 by Aro et al. [26] evaluating rhBMP-2 addition for tibial fractures treatment. Three hundred patients were enrolled: 136 underwent IM fixation and 139 received IM fixation with rhBMP-2 in combination with ACS. The healing of tibial fractures was not significantly accelerated by the addition of rhBMP-2, although the chance of secondary intervention and invasive post surgery procedures was higher in the control group. However, the authors also described that the incidence of infection was higher in the rhBMP-2 group. Similarly, in 2013 Lyon et al. [30] showed no significant difference with or without rhBMP-2 for the treatment of tibial fractures: 62 patients received IM treatment, 122 patients received IM fixation with $1 \mathrm{mg} / \mathrm{ml}$ (low dose) of rhBMP-2 injection in a calcium phosphate matrix (CPM), 125 patients received IM fixation with $2 \mathrm{mg} / \mathrm{ml}$ (high dose) of rhBMP-2/CPM injection, and 60 patients IM fixation with buffer/CPM injection. After a mean follow-up of 13 months, the time to radiographic fracture union of the experimental groups was not improved. Likewise, pain free full-weight bearing was not significantly improved by both dosages of rhBMP-2/CPM and the rhBMPs group experienced more adverse events (as heterotopic ossification, oedema) compared with the IM or IM/buffer groups.

\section{rhBMP-7 and fractures}

In 2002, Maniscalco et al. [31] investigated the effect of external fixation (EF) with or without rhBMP-7 for the treatment of tibial fractures in 14 patients (seven patients EF and seven patients EF+ rhBMP-7). After 6 months, all patients had bony consolidation and no intra- or post-operative complications, with analogous healing time. In 2005, the Canadian Orthopaedic Trauma Society [32] evaluated the safety and efficacy of rhBMP-7 for tibial shaft fractures healing. The study consisted of 124 patients divided into two groups with 62 patients in the standard care IM treatment and 62 patients in the rhBMP-7 group. After 6 months, the incidence of delayed union, non-union, and secondary intervention was significantly lower in the rhBMP-7 group, which also presented a radiographically increased union rate with no adverse reactions.

\section{BMPs and non-unions}

The literature search for BMPs use in non-unions identified: 3 RCTs, 4 comparative studies, 15 case series, and 3 case reports. The anatomical location included a multitude of sites in 12 studies, such as femur, tibia, humerus, ulna etc., 7 papers treated tibial non-unions, 4 humeral non-unions, 1 ulna nonunions, and 1 femoral non-unions (Table 2).

\section{rhBMP-7 and non-unions}

In 2001, Friedlaender et al. [14] investigated safety and efficacy of rhBMP-7 in treating tibial non-unions: 122 patients (124 limbs) were divided into 61 patients receiving a combination of rhBMP-7 and type I collagen powder and 61 patients receiving $\mathrm{ABG}$; all patients underwent $\mathrm{IM}$ fixation. At 9 and 24 months, all treated non-unions healed without differences between groups. In 2006, Calori et al. [42] compared safety and efficacy of rhBMP-7 and platelet-rich plasma (PRP) as biological augmentation for the treatment of non-unions in different anatomical sites. The study design included 29 patients treated with homologous or heterologous grafts divided into 16 patients receiving rhBMP-7 and 13 PRP placed directly within the graft. Preliminary results showed that rhBMP-7 seemed to be more effective, with higher healing rate and lower failure rate. These results were later confirmed in 2008 during the final analysis of this study [13] on a large cohort of 120 patients: 60 patients in each group. Clinical and radiological unions were superior in the rhBMP-7 group, also showing a lower radiographic healing time.

\section{Complications}

The use of BMPs raised some concerns on safety issues due to several negative effects that have been reported. The most severe complications were described in spine surgery, where the use of rhBMP-2 was associated with an increasing rate of vertebral osteolysis, graft subsidence, graft migration, formation of neutralizing antibodies against BMPs, radiculitis, haematoma or seroma, ectopic bone formation, pulmonary and neurological complications [60-62]. Due to these problems and to the high proportion of surgery performed with BMPs deviating for the original approved indications [63], the FDA issued a warning regarding the off label use of rhBMP-2 (INFUSE®) in cervical spine [64].

Considering the potential adverse events of BMPs, this systematic review on the treatment of bone fractures, non union, and osteonecrosis, also focused on the literature evidence of complications related to these orthopaedic conditions. The analysis of the comparative studies underlining a higher percentage of complications, showed that the majority of complications after BMPs treatment were related to heterotopic ossification, which were reported in 3 papers on fracture repair [25, 29, 34], in 2 papers on non union treatment [40, 44], and in 1 paper on osteonecrosis [59] involving both rhBMP-2 and 7. Moreover, other described complications were infections [26, 55], peripheral oedema, heterotopic ossification/soft-tissues calcification, new or increased pain 
[26], and the development of distal tibiofibular synostosis (1/52) described with rhBMP-7 for non-union treatment [52].

Finally, regarding systemic reactions related to the use of BMPs, only 1 paper by Aro et al. [26] described elevated titres of rhBMP-2 antibody levels in $2 \%$ of patients. Interestingly, no clear association between immune response and reported adverse events or lack of efficacy was observed. All other papers did not report any systemic or allergic reactions following BMPs administration.

\section{Economical aspects}

Although there is currently good evidence supporting the efficacy and safety of BMPs in the treatment of fractures and non-unions, concerns are still raised about cost implications associated with its use. Considering the application in fractures repair, Alt el al. [65] showed that the use of rhBMP-2 reduced secondary interventions in patients with grade III tibial fractures treated with an unreamed nail, leading to net financial savings in Germany, France, and the UK. With regard to non-unions, a prospective non-randomized study conducted by Dahabreh et al. [66] demonstrated that the cost implications associated with the use of rhBMP-7 for the treatment of tibial non-unions were being offset by a reduction in other costs incurred with iliac crest bone grafting. Moreover, the same research group also suggested that the financial burden on the hospital could be reduced by early rhBMP-7 administration whenever a non-union fracture was present or anticipated. Finally, Calori et al. [67] performed a regional cost analysis on the Italian healthcare system for the use of rhBMP-7. The study demonstrated that, without appropriate reimbursement, the hospital underwent significantly higher surgical expenses when using rhBMP-7 instead of a gold standard technique (ABG). However, in contrast to these losses, the costs incurred during the follow-up were on average higher in patients treated with $\mathrm{ABG}$ compared to those receiving rhBMP-7.

\section{Discussion}

This systematic review highlighted that the clinical use of BMPs is a promising tool in supporting bone regeneration.

These positive findings explain the interest on this topic, which is also confirmed by the numerous (more than 50) ongoing clinical trials on BMPs in bone regeneration found at clinical trials.gov. On the other hand, this literature research also revealed that most of the clinical findings are based on case reports or case series with small patient populations, characterized by different delivery approaches, anatomical locations, bone pathologies and dosages, which makes it difficult to draw any final conclusion about the real potential of BMPs therapy and the best protocol they can be applied to
[43-59]. Therefore, further research in this direction is needed.

Bone pathologies such as fractures, non-union or osteonecrosis represent a significant challenge for orthopaedic surgeons. Among the 6.2 million fractures occurring annually in the United States, 5 to $10 \%$ on average develop into delayed unions or non-unions with great expenditure for the national health system in terms of costs and work force loss [47]. In this scenario, BMPs have been suggested as a promising treatment approach for bone repair, since they are considered the most potent osteoinductive agents [68]. However, this systematic review found mixed results among the available RCTs and comparative papers: 11 reported positive results for BMPs augmentation, 3 obtained no significant effects, and 2 showed negative results.

Besides mixed results, the difficulties in drawing clear conclusions on BMPs are also due to the heterogeneity of the published studies, mostly in terms of different BMPs applied, with different concomitant treatments for each bone pathology.

In fracture healing, the most used rhBMPs is the type 2 described in 10 papers, while 4 papers were about rhBMP-7, and 1 paper used both rhBMPs. Among RCT and comparative trials, 5 papers reported positive results, 2 no significant effects, and 2 negative results. rhBMPs were effective in accelerating tibial fractures healing, reducing the frequency of secondary interventions and the rate of infections $[12,16,23,32$, 33]. Moreover, they showed to be a valid approach in combination with allografts, as an alternative to $\mathrm{ABG}$, leading to the same beneficial effects but avoiding the drawbacks related to invasive autologous bone harvesting procedures [23]. The negative results reported were related to the higher rate of complications in the rhBMPs group, i.e., heterotopic ossification or calcification [25, 30], local oedema, or calcinosis [30].

For non-union treatment, the most used rhBMPs was the type 7 with 21 papers, 3 used rhBMP-2, and 1 compared type 2 and 7. Among RCTs and comparative studies, all 6 papers reported superior results with rhBMPs, in terms of clinical outcome, radiographic consolidation, and healing time acceleration [13, 14, 36, 42, 48, 54]. Moreover, rhBMPs provided comparable results to $\mathrm{ABG}$ treatment $[14,48,54]$ with shorter operative time, reduced operative blood loss, and avoiding donor site morbidity [14, 36]. Regarding safety, comparative studies did not show a higher complication rate, with some adverse events reported only in 3 non-comparative papers [40, 44, 52] describing cases of heterotopic ossification $[40,44]$ or tibiofibular synostosis [52].

Finally, little evidence has been reported on osteonecrosis, with four published studies, one of which was comparative [17] and described similar results with or without rhBMPs. No complications or adverse events have been reported in these studies. 
In general, while there is a tendency to use rhBMPs for certain indications, there is no consensus about the best BMPs for the regeneration of each specific bone pathology and the only comparison was performed by Conway et al. [56] in a retrospective study, with a higher and faster rate of radiographic bone non-union healing with rhBMP-2 compared to rhBMP-7, and no difference in the complication rate between groups. However, the overall lack of well-designed comparative studies prevents determining if both BMPs are equally effective or if they differ in terms of enhancement potential of bone healing in heterogeneous orthopaedic conditions.

Another critical point is the delivery method, since most of the available commercial products combined BMPs with biomaterials, and structural and biomechanical properties of carriers are considered key aspects for the modulation of BMPs availability at the site of injury [69]. In fact, these molecules are relatively soluble, and if not maintained by an appropriate carrier, they will be cleared from the site and diffuse into adjacent undesirable tissues, promoting adverse reactions (such as ectopic bone formation) [69]. Several materials have been tested in pre-clinical settings, such as collagen, calcium phosphate ceramics, and synthetic polymers but only bovine collagen based BMPs delivery devices (ACS or powder) with official approval for clinical use were documented [70]. Despite the use of delivery devices, large doses of BMPs are required to achieve the desired osteogenic effects, which makes the procedure expensive and increases the risk of clinical complications related to their supra-physiological concentration [71]. Therefore, new solutions for BMPs delivery able to maintain a more sustained and effective release pattern still need to be explored.

\section{Conclusion}

This systematic review showed controversial clinical evidence on BMPs use for the treatment of fractures, non union, and osteonecrosis. Knowledge on this topic is still preliminary and the few available reports are mainly of low quality. While positive findings have been described in many studies, overall literature still presents mixed results in terms of efficacy and adverse events. The difficulties in drawing clear conclusions on BMPs are also due to the heterogeneity of the published studies, mostly in terms of different BMPs applied, with different concomitant treatments for each bone pathology. Further well designed comparative studies are needed to confirm the promising findings and optimize BMP use both in terms of best delivery method and most successful indications for the treatment of bone pathologies.
Acknowledgements This work was partially supported by the European Union Seventh Framework Programme FP7- PEOPLE-2013ITN under Grant Agreement no. 607051-Bioinspire: Training program on new bioinspired bone regeneration.

\section{Compliance with ethical standards}

Conflict of interest Elizaveta Kon declares: Zimmer-Biomet (USA): Paid presenter or speaker. Cartiheal (Israel): Paid consultant; Stock or stock options. Fidia (Italy): Paid presenter or speaker. Finceramica (Italy): Paid presenter or speaker. International Cartilage Repair Society: Board or committee member. Journal of Experimental Orthopaedics: Editorial or governing board. Giuseppe Filardo declares:

Zimmer-Biomet (USA): Institutional Support.

Cartiheal (Israel): Consultant and Institutional Support.

Fidia (Italy): Consultant and Institutional Support.

Finceramica (Italy): Consultant and Institutional Support.

Green Bone (Italy): Consultant and Institutional Support.

DSM Biomedical (USA): Institutional Support.

IGEA Clinical Biophisic: Institutional Support.

PIRAMAL/ Smith-Nephew: Institutional Support.

All the other authors declare that there are no competing interests regarding the publication of this paper.

Open Access This article is distributed under the terms of the Creative Commons Attribution 4.0 International License (http:// creativecommons.org/licenses/by/4.0/), which permits unrestricted use, distribution, and reproduction in any medium, provided you give appropriate credit to the original author(s) and the source, provide a link to the Creative Commons license, and indicate if changes were made.

\section{References}

1. Nauth A, Ristevski B, Li R, Schemitsch EH (2011) Growth factors and bone regeneration: how much bone can we expect? Injury 42(6):574-579

2. Argintar E, Edwards S, Delahay J (2011) Bone morphogenetic proteins in orthopaedic trauma surgery. Injury 42(8):730-734

3. Dimitriou R, Tsiridis E, Carr I, Simpson H, Giannoudis PV (2006) The role of inhibitory molecules in fracture healing. Injury 37(Suppl 1):S20-S29

4. Dimitriou R, Giannoudis PV (2005) Discovery and development of BMPs. Injury 36(Suppl 3):S28-S33

5. Ronga M, Fagetti A, Canton G, Paiusco E, Surace MF, Cherubino P (2013) Clinical applications of growth factors in bone injuries: experience with BMPs. Injury 44(Suppl 1):S34-S39

6. Schmidmaier G, Capanna R, Wildemann B, Beque T, Lowenberg D (2009) Bone morphogenetic proteins in critical-size bone defects: what are the options? Injury 40(Suppl 3):S39-S43

7. Cho TJ, Gerstenfeld LC, Einhorn TA (2002) Differential temporal expression of members of the transforming growth factor beta superfamily during murine fracture healing. J Bone Miner Res 17(3): 513-520

8. Yu YY, Lieu S, Lu C, Miclau T, Marcucio RS, Colnot C (2010) Immunolocalization of BMPs, BMP antagonists, receptors, and effectors during fracture repair. Bone 46(3):841-851

9. Keskin DS, Tezcaner A, Korkusuz P, Korkusuz F, Hasirci V (2005) Collagen-chondroitin sulfate-based PLLA-SAIB-coated rhBMP-2 delivery system for bone repair. Biomaterials 26(18):4023-4034 
10. Zara JN, Siu RK, Zhang X, Shen J, Ngo R, Lee M, Li W, Chiang M, Chung J, Kwak J, Wu BM, Ting K, Soo C (2011) High doses of bone morphogenetic protein 2 induce structurally abnormal bone and inflammation in vivo. Tissue Eng Part A 17(9-10):1389-1399

11. Yang HS, La WG, Bhang SH, Lee TJ, Lee M, Kim BS (2011) Apatite-coated collagen scaffold for bone morphogenetic protein2 delivery. Tissue Eng Part A 17(17-18):2153-2164

12. Govender S, Csimma C, Genant HK, Valentin-Opran A, (BESTT) study group (2002) Recombinant human bone morphogenetic protein-2 for treatment of open tibial fractures: a prospective, controlled, randomized study of four hundred and fifty patients. J Bone Joint Surg Am 84-A(12):2123-2134

13. Calori GM, Tagliabue L, Gala L, d'Imporzano M, Peretti G, Albisetti W (2008) Application of rhBMP-7 and platelet-rich plas$\mathrm{ma}$ in the treatment of long bone non-unions: a prospective randomised clinical study on 120 patients. Injury 39(12):13911402

14. Friedlaender GE, Perry CR, Cole JD, Cook SD, Cierny G, Muschler GF, Zych GA, Calhoun JH, LaForte AJ, Yin S (2001) Osteogenic protein-1 (bone morphogenetic protein-7) in the treatment of tibial nonunions. J Bone Joint Surg Am 83-A(Suppl 1): S151-S158

15. Giannoudis PV, Tzioupis C (2005) Clinical applications of BMP-7: the UK perspective. Injury 36(Suppl 3):S47-S50

16. Swiontkowski MF, Aro HT, Donell S, Esterhai JL, Goulet J, Jones A, Kregor PJ, Nordsletten L, Paiement G, Patel A (2006) Recombinant human bone morphogenetic protein-2 in open tibial fractures. A subgroup analysis of data combined from two prospective randomized studies. J Bone Joint Surg Am 88(6):1258-1265

17. Sun W, Li Z, Gao F, Shi Z, Zhang Q, Guo W (2014) Recombinant human bone morphogenetic protein- 2 in debridement and impacted bone graft for the treatment of femoral head osteonecrosis. PLoS One 9(6):e100424

18. Arrabal PM, Visser R, Santos-Ruiz L, Becerra J, Cifuentes M (2013) Osteogenic molecules for clinical applications: improving the BMP-collagen system. Biol Res 46(4):421-429

19. Einhorn TA (2003) Clinical applications of recombinant human BMPs: early experience and future development. J Bone Joint Surg Am 85:82-88

20. Gupta MC, Maitra S (2002) Bone grafts and bone morphogenetic proteins in spine fusion. Cell Tissue Bank 3(4):255-267

21. Carlisle E, Fischgrund JS (2005) Bone morphogenetic proteins for spinal fusion. Spine J 5(6 Suppl):240S-249S

22. Robinson Y, Heyde CE, Tschöke SK, Mont MA, Seyler TM, Ulrich SD (2008) Evidence supporting the use of bone morphogenetic proteins for spinal fusion surgery. Expert Rev Med Devices 5(1): $75-84$

23. Jones AL, Bucholz RW, Bosse MJ, Mirza SK, Lyon TR, Webb LX, Pollak AN, Golden JD, Valentin-Opran A, BMP-2 Evaluation in Surgery for Tibial Trauma-Allgraft (BESTT-ALL) Study Group (2006) Recombinant human BMP-2 and allograft compared with autogenous bone graft for reconstruction of diaphyseal tibial fractures with cortical. J Bone Joint Surg Am 88(7):1431-1441

24. Schwartz ND, Hicks BM (2008) Eight-centimeter segmental ulnar defect treated with recombinant human bone orphogenetic protein2. Am J Orthop (Belle Mead NJ) 37(11):569-571

25. Boraiah S, Paul O, Hawkes D, Wickham M, Lorich DG (2009) Complications of recombinant human BMP-2 for treating complex tibial plateau fractures: a preliminary report. Clin Orthop Relat Res 467(12):3257-3262

26. Aro HT, Govender S, Patel AD, Hernigou P, Perera de Gregorio A, Popescu GI, Golden JD, Christensen J, Valentin A (2011) Recombinant human bone morphogenetic protein-2: a randomized trial in open tibial fractures treated with reamed nail fixation. J Bone Joint Surg Am 93(9):801-808
27. Capo JT, Marcus MS, Shamian B (2011) Treatment of a segmental defect in open radial and ulnar shaft fractures using rhBMP-2 and iliac crest bone graft: a case report. Hand (New York) 6(4):424-428

28. Baltzer AW, Ostapczuk MS, Stosch D, Granrath M (2012) The use of recombinant human bone morphogenetic protein-2 for the treatment of a delayed union following femoral neck open-wedge osteotomy. Orthop Rev (Pavia) 4(1):e4

29. Julka A, Shah AS, Miller BS (2012) Inflammatory response to recombinant human bone morphogenetic protein-2 use in the treatment of a proximal humeral fracture: a case report. J Shoulder Elb Surg 21(1):e12-e16

30. Lyon T, Scheele W, Bhandari M, Koval KJ, Sanchez EG, Christensen J, Valentin A, Huard F (2013) Efficacy and safety of recombinant human bone morphogenetic protein-2/calcium phosphate matrix for closed tibial diaphyseal fracture: a double-blind, randomized, controlled phase-II/III trial. J Bone Joint Surg Am 95(23):2088-2096

31. Maniscalco P, Gambera D, Bertone C, Rivera F, Crainz E, Urgelli S (2002) Healing of fresh tibial fractures with OP-1. A preliminary report. Acta Biomed 73(1-2):27-33

32. McKee MD (2005) Recombinant human bone morphogenic protein-7: applications for clinical trauma. J Orthop Trauma 19(10 Suppl):S26-S28

33. Ristiniemi J, Flinkkila T, Hyvonen P, Lakovaara M, Pakarinen H, Jalovaara P (2007) RhBMP-7 accelerates the healing in distal tibial fractures treated by external fixation. J Bone Joint Surg Br 89:265272

34. Axelrad TW, Steen B, Lowenberg DW, Creevy WR, Einhorn TA (2008) Heterotopic ossification after the use of commercially available recombinant human bone morphogenetic proteins in four patients. J Bone Joint Surg Br 90:1617-1622

35. Crawford CH, Seligson D (2009) Atrophic nonunion of humeral diaphysis treated with locking plate and recombinant bone morphogenetic protein: nine cases. Am J Orthop (Belle Mead NJ) 38(11): $567-570$

36. Tressler MA, Richards JE, Sofianos D, Comrie FK, Kregor PJ, Obremskey WT (2011) Bone morphogenetic protein-2 compared to autologous iliac crest bone graft in the treatment of long bone nonunion. Orthopedics 34(12):e877-e884

37. Desai PP, Bell AJ, Suk M (2010) Treatment of recalcitrant, multiply operated tibial nonunions with the RIA graft and rh-BMP2 using intramedullary nails. Injury 41(Suppl 2):S69-S71

38. Pecina M, Haspl M, Jelic M, Vukicevic S (2003) Repair of a resistant tibial non-union with a recombinant bone morphogenetic protein-7 (rh-BMP-7). Int Orthop 27:320-332

39. Kujala S, Raatikainen T, Ryhänen J, Kaarela O, Jalovaara P (2004) Composite implant of native bovine bone morphogenetic protein (BMP), collagen carrier and biocoral in the treatment of resistant ulnar nonunions: report of five preliminary cases. Arch Orthop Trauma Surg 1:26-30

40. Bong MR, Capla EL, Egol KA, Sorkin AT, Distefano M, Buckle R, Chandler RW, Koval KJ (2005) Osteogenic protein-1 (bone morphogenic protein-7) combined with various adjuncts in the treatment of humeral diaphyseal nonunions. Bull Hosp Jt Dis 63(1-2):20-23

41. Dimitriou R, Dahabreh Z, Katsoulis E, Matthews SJ, Branfoot T, Giannoudis PV (2005) Application of recombinant BMP-7 on persistent upper and lower limb non-unions. Injury 36(Suppl 4):S51S59

42. Calori GM, D'Avino M, Tagliabue L, Albisetti W, d'Imporzano M, Peretti G (2006) An ongoing research for evaluation of treatment with BMPs or AGFs in long bone non-union: protocol description and preliminary results. Injury 37(Suppl 3):S43-S50

43. Ronga M, Baldo F, Zappala G, Cherubino P (2006) Recombinant human bone morphogenetic protein-7 for treatment of long bone 
non-union: an observational, retrospective, non-randomized study of 105 patients. Injury 37(Suppl 3):S51-S56

44. Wysocki RW, Cohen MS (2007) Ectopic ossification of the triceps muscle after application of bone morphogenetic protein-7 to the distal humerus for recalcitrant nonunion: a case report. J Hand Surg Am 32(5):647-650

45. Kanakaris NK, Calori GM, Verdonk R, Burssens P, De Biase P, Capanna R, Vangosa LB, Cherubino P, Baldo F, Ristiniemi J, Kontakis G, Giannoudis PV (2008) Application of BMP-7 to tibial non-unions: a 3-year multicenter experience. Injury 39(Suppl 2): S83-S90

46. Desmyter S, Goubau Y, Benahmed N, de Wever A, Verdonk R (2008) The role of bone morphogenetic protein-7 (osteogenic protein-1) in the treatment of tibial fracture non-unions. An overview of the use in Belgium. Acta Orthop Belg 74(4):534-537

47. Giannoudis PV, Kanakaris NK, Dimitriou R, Gill I, Kolimarala V, Montgomery RJ (2009) The synergistic effect of autograft and BMP-7 in the treatment of atrophic nonunions. Clin Orthop Relat Res 467(12):3239-3248

48. Zimmermann G, Wagner C, Schmeckenbecher K, Wentzensen A, Moghaddam A (2009) Treatment of tibial shaft non-unions: bone morphogenetic proteins versus autologous bone graft. Injury 40(Suppl 3):S50-S53

49. Kanakaris NK, Lasanianos N, Calori GM, Verdonk R, Blokhuis TJ, Cherubino P, De Biase P, Giannoudis PV (2009) Application of bone morphogenetic proteins to femoral non-unions: a 4-year multicentre experience. Injury 40(Suppl 3):S54-S61

50. Moghaddam A, Elleser C, Biglari B, Wentzensen A, Zimmermann G (2010) Clinical application of BMP 7 in long bone non-unions. Arch Orthop Trauma Surg 130:71-76

51. O'hEireamhoin S, Quinlan JF, Rourke KO (2011) The use of bone morphogenetic protein 7 in fracture non-unions. Orthop Surg 3(1): 40-44

52. Papanna MC, Al-Hadithy N, Somanchi BV, Sewell MD, Robinson PM, Khan SA, Wilkes RA (2012) The use of bone morphogenic protein-7 (OP-1) in the management of resistant non-unions in the upper and lower limb. Injury 43(7):1135-1140

53. Murena L, Canton G, Vulcano E, Surace MF, Cherubino P (2014) Treatment of humeral shaft aseptic nonunions in elderly patients with opposite structural allograft, BMP-7, and mesenchymal stem cells. Orthopedics 37(2):e201-e206

54. Calori GM, Colombo M, Bucci M, Mazza EL, Fadigati P, Mazzola S (2015) Clinical effectiveness of Osigraft in long-bones nonunions. Injury 46(Suppl 8):S55-S64

55. Ollivier M, Gay AM, Cerlier A, Lunebourg A, Argenson JN, Parratte S (2015) Can we achieve bone healing using the diamond concept without bone grafting for recalcitrant tibial nonunions? Injury 46(7):1383-1388

56. Conway JD, Shabtai L, Bauernschub A, Specht SC (2014) BMP-7 versus BMP-2 for the treatment of long bone nonunion. Orthopedics 37(12):e1049-e1057

57. Lieberman JR, Conduah A, Urist MR (2004) Treatment of osteonecrosis of the femoral head with core decompression and human bone morphogenetic protein. Clin Orthop Relat Res 429: $139-145$
58. Marsell R, Hailer NP (2014) Successful treatment of a humeral capitulum osteonecrosis with bone morphogenetic protein-7 combined with autologous bone grafting. Ups J Med Sci 119:287-289

59. Papanagiotou M, Malizos KN, Vlychou M, Dailiana ZH (2014) Autologous (non-vascularised) fibular grafting with recombinant bone morphogenetic protein-7 for the treatment of femoral head osteonecrosis: preliminary report. Bone Joint J 96-B(1):31-35

60. Cole T, Veeravagu A, Jiang B, Ratliff JK (2014) Usage of recombinant human bone morphogenetic protein in cervical spine procedures: analysis of the MarketScan longitudinal database. J Bone Joint Surg Am 96(17):1409-1416

61. Garrett MP, Kakarla UK, Porter RW, Sonntag VK (2010) Formation of painful seroma and edema after the use of recombinant human bone morphogenetic protein-2 in posterolateral lumbar spine fusions. Neurosurgery 66(6):1044-1049

62. Hoffmann MF, Jones CB, Sietsema DL (2013) Complications of rhBMP-2 utilization for posterolateral lumbar fusions requiring reoperation: a single practice, retrospective case series report. Spine J 13(10):1244-1252

63. Faundez A, Tournier C, Garcia M, Aunoble S, Le Huec JC (2016) Bone morphogenetic protein use in spine surgery-complications and outcomes: a systematic review. Int Orthop 40(6):1309-1319

64. Carragee EJ, Hurwitz EL, Weiner BK (2011) A critical review of recombinant human bone morphogenetic protein-2 trials in spinal surgery: emerging safety concerns and lessons learned. Spine J 11(6):471-491

65. Alt V, Donell ST, Chhabra A, Bentley A, Eicher A, Schnettler R (2009) A health economic analysis of the use of rhBMP-2 in Gustilo-Anderson grade III open tibial fractures for the UK, Germany, and France. Injury 40(12):1269-1275

66. Dahabreh Z, Calori GM, Kanakaris NK, Nikolaou VS, Giannoudis PV (2009) A cost analysis of treatment of tibial fracture nonunion by bone grafting or bone morphogenetic protein-7. Int Orthop 33(5):1407-1414

67. Giorgio Calori M, Capanna R, Colombo M, De Biase P, O'Sullivan C, Cartareggia V, Conti C (2013) Cost effectiveness of tibial nonunion treatment: a comparison between rhBMP-7 and autologous bone graft in two Italian centres. Injury 44(12):1871-1879

68. Oryan A, Alidadi S, Moshiri A, Bigham-Sadegh A (2014) Bone morphogenetic proteins: a powerful osteoinductive compound with non-negligible side effects and limitations. Biofactors 40(5):459 481

69. Tannoury CA, An HS (2014) Complications with the use of bone morphogenetic protein 2 (BMP-2) in spine surgery. Spine J 14(3): $552-559$

70. Han D, Liu W, Ao Q, Wang G (2008) Optimal delivery systems for bone morphogenetic proteins in orthopedic applications should model initial tissue repair structures by using a heparinincorporated fibrin-fibronectin matrix. Med Hypotheses 71(3): 374-378

71. Haidar ZS, Hamdy RC, Tabrizian M (2009) Delivery of recombinant bone morphogenetic proteins for bone regeneration and repair. Part B: delivery systems for BMPs in orthopaedic and craniofacial tissue engineering. Biotechnol Lett 31(12):1825-1835 